\title{
Health Information Systems - Technology and Acceptance
}

\section{Findings from the Section on Health Information Systems}

\author{
0.J. Bott, Managing Editor for the IMIA Yearbook Section on Health Information Systems \\ Technical University of Braunschweig, Institute of Medical Informatics, Braunschweig, Germany
}

\section{Introduction}

Health information systems (HIS) have a wide spectrum of research topics [1, 2]. Methodical aspects concern HIS management [3], their analysis, design, and evolution [4, 5], HIS evaluation $[6,7]$ and technology assessment [8]. In spite of all progress that has been made in these fields success of HIS projects still is not guaranteed [9]. This is impressively demonstrated by the ongoing discussion concerning the implementation and introduction of computerized physician order entry systems [10,11]. Another important HIS application field are transinstitutional health information systems to support shared care concepts on a regional or national level [12], together with interoperability [13] and technological aspects of such systems [14, 15]. Especially driven by the discussion concerning the aging society, IT-based home care and telecare for the elderly [16] respectively for patients with chronic diseases $[17,18]$ are intensively discussed. Research on this field is synergistically accompanied by progress in sensor technology and sensor data analysis e.g. in the area of activity measurement [19].

\section{Best Paper Selection}

The best paper selection of articles for the IMIA Yearbook 2007 section 'health information systems' follows the tradition of previous yearbooks $[20,21]$ and reflects this broad spectrum of topics. This years selection presents examples of outstanding research on new user interfaces for mobile data entry, smart card based approaches for national eHealth projects, system architectures for telemedicine services, new approaches for electronic prescriptions, and telemedical systems for chronic care in COPD.

The five articles were selected from three international peer reviewed journals in the fields of medicine and medical informatics. Table 1 presents the selected papers. A brief content summary of the selected best papers can be found in the appendix of this report.

\section{Conclusions and Outlook}

The best paper selection again demonstrates that telemedicine solutions for telecare or home care have the potential to improve quality and outcome of health care. The results of a clinical study presented by Toledo et al. in [22] exemplify this impressively for the application field of chronic care for COPD. Based on experiences like this for COPD and other diseases current research is now directed towards general architectural aspects of telemedical systems and their integration in HIS. This is demonstrated by Maglaveras et 
Table 1 Best paper selection of articles for the IMIA Yearbook of Medical Informatics 2007 in the section 'Health Information Systems'. The articles are listed in alphabetical order of the first author's surname.

\section{Section}

Health Information Systems

- Despont-Gros C, Landau R, Rutschmann 0, Simon J, Lovis C. The digital pen and paper. Evaluation and acceptance of a new data acquisition device in clinical settings. Methods Inf Med 2005;44(3):359-68.

- Ghinea G, Asgari S, Moradi A, Serif T. A Jini-based solution for electronic prescriptions. IEEE Trans Inf Technol Biomed 2006;10(4):794-802.

- Liu CT, Yang PT, Yeh YT, Wang BL. The impacts of smart cards on hospital information systems--an investigation of the first phase of the national health insurance smart card project in Taiwan. Int J Med Inform 2006;75(2):173-81.

- Maglaveras N, Chouvarda I, Koutkias VG, Gogou G, Lekka I, Goulis D, Avramidis A, Karvounis C, Louridas G, Balas EA. The Citizen Health System (CHS): a modular medical contact center providing quality telemedicine services. IEEE Trans Inf Technol Biomed 2005;9(3):353-62.

- de Toledo P, Jimenez S, del Pozo F, Roca J, Alonso A, Hernandez C. Telemedicine experience for chronic care in COPD. IEEE Trans Inf Technol Biomed 2006;10(3):567-73

al. with their middleware based telemedical platform for supporting monitoring, treatment, and management of chronically ill patients at home [14]. A lot of countries did initiate projects concerning the introduction of an eHealth infrastructure to support systematically shared care concepts and to improve the efficiency of their health care system. Changes in health care processes and organization are the consequences. This implicates the need for research on the impacts of introducing new eHealth technologies. Liu et al. analysed the impacts on hospital information systems of introducing patient smart cards nationwide and draw conclusions usable for similar projects [23]. Like smart cards, also electronic prescriptions are an often discussed approach towards optimizing health care systems. In contrast to card based solutions Ghinea et al. proposed a system based on ubiquitous computing technology and analysed feasibility and acceptance of their approach [24]. The technology oriented study presents interesting insights in potential alternatives to traditional approaches for realizing electronic prescriptions and their communication.
Since the very beginning of utilizing computer technology in health care one of the major problems is related to a suitable design of user interfaces for software applications. McDonald already in 1992 wrote "the difficult side of computer-stored medical records systems [is]: getting the data in" [25]. Intuitive user interfaces remain a main success factor for health informatics applications [9]. The study of DespontGros et al. focusses on a new data acquisition device, the digital pen and paper, and elaborates systematically its potentials and limitations [26].

Thus research on evaluation and general architectural aspects of telemedical platforms and eHealth infrastructures remains an important topic together with aspects of identifying suitable new technologies and establishing their acceptance from the users' and the organizations' point of view.

Up-to-date information about current and future issues of the IMIA Yearbook is available at http://www.schattauer.de/ index.php?id=1384

\section{Acknowledgement}

We greatly acknowledge the support of Martina Hutter and of the reviewers in the selection process of the IMIA yearbook.

\section{References}

1. Kuhn KA, Wurst SH, Bott OJ, Giuse DA. Expanding the scope of health information systems. Challenges and developments. Methods Inf Med 2006;45 Suppl 1:43-52.

2. Haux R. Health information systems - past, present, future. Int J Med Inform 2006;75(3-4):268-81.

3. Winter A, Brigl B, Funkat G, Haber A, Heller O, Wendt T. 3LGM(2)-Modelling to Support Management of Health Information Systems. Stud Health Technol Inform 2005;116:491-6.

4. Lenz R, Buessecker F, Herlofsen H, Hinrichs F, Zeiler T, Kuhn KA. Demand-driven evolution of IT systems in healthcare - a case study for improving interdisciplinary processes. Methods Inf Med 2005;44(1):4-10.

5. Bott OJ, Bergmann J, Hoffmann I, Vering T, Gomez EJ, Hernando ME, et al. Analysis and Specification of Telemedical Systems Using Modelling and Simulation: the MOSAIK-M Approach. Stud Health Technol Inform 2005;116:503-8.

6. Ammenwerth E, de Keizer N. An inventory of evaluation studies of information technology in health care trends in evaluation research 1982-2002. Methods Inf Med 2005;44(1):44-56.

7. Moehr JR, Anglin C, Schaafsma J, Pantazi S, Grimm N. Lest formalisms impede insight and success: evaluation in health informatics - a case study. Methods Inf Med 2006;45(1):67-72.

8. Ammenwerth E. Health technology assessment. Findings from the section on assessing information technologies for health. Methods Inf Med 2006;45 Suppl 1:16-9.

9. Brender J, Ammenwerth E, Nykanen P, Talmon J. Factors influencing success and failure of health informatics systems - a pilot Delphi study. Methods Inf Med 2006;45(1):125-36.

10. Ammenwerth E, Talmon J, Ash JS, Bates DW, Beuscart-Zephir MC, Duhamel A, et al. Impact of CPOE on mortality rates - contradictory findings, important messages. Methods Inf Med 2006; 45(6):586-93.

11. Aarts J, Doorewaard H, Berg M. Understanding implementation: the case of a computerized physician order entry system in a large Dutch university medical center. J Am Med Inform Assoc 2004;11(3):207-16.

12. Haux R. Individualization, globalization and health-about sustainable information technologies and the aim of medical informatics. Int J Med Inform 2006;75(12):795-808.

13. Lenz R, Beyer M, Kuhn KA. Semantic integration in healthcare networks. Int J Med Inform 2007;76(23):201-7.

14. Maglaveras N, Chouvarda I, Koutkias VG, Gogou G, Lekka I, Goulis D, et al. The Citizen Health System (CHS): a modular medical contact center providing quality telemedicine services. IEEE Trans Inf Technol Biomed 2005;9(3):353-62.

15. SchabetsbergerT,Ammenwerth E, Andreatta S, Gratl G, Haux R, Lechleitner G, et al. From a paperbased transmission of discharge summaries to electronic communication in health care regions. Int J Med Inform 2006;75(3-4):209-15. 
16. Bricon-Souf N, Anceaux F, Bennani N, Dufresne E, Watbled L. A distributed coordination platform for home care: analysis, framework and prototype. Int J Med Inform 2005;74(10):809-25.

17. Larizza C, Bellazzi R, Stefanelli M, Ferrari P, De Cata P, Gazzaruso C, et al. The M2DM Projectthe experience of two Italian clinical sites with clinical evaluation of a multi-access service for the management of diabetes mellitus patients. Methods Inf Med 2006;45(1):79-84.

18. Lin CC, Chiu MJ, Hsiao CC, Lee RG, Tsai YS Wireless health care service system for elderly with dementia. IEEE Trans Inf Technol Biomed 2006;10(4):696-704.

19. Parkka J,Ermes M, Korpipaa P, Mantyjarvi J, Peltola J, Korhonen I. Activity classification using realistic data from wearable sensors. IEEE Trans InfTechnol Biomed 2006;10(1):119-28.

20. Bott OJ, Ammenwerth E, Brigl B, Knaup P, Lang $\mathrm{E}$, Pilgram R, et al. The challenge of ubiquitous computing in health care: technology, concepts and solutions. Findings from the IMIA Yearbook of Medical Informatics 2005. Methods Inf Med 2005;44(3):473-9.

21. Bott OJ. Health information systems: between shared care and body area networks. Methods Inf Med 2006;45 Suppl 1:53-4.

22. de Toledo P, Jimenez S, del Pozo F, Roca J, Alonso A, Hernandez C. Telemedicine experience for chronic care in COPD. IEEE Trans Inf Technol Biomed 2006;10(3):567-73.

23. Liu CT, Yang PT, Yeh YT, Wang BL. The impacts of smart cards on hospital information systemsan investigation of the first phase of the national health insurance smart card project in Taiwan. Int J Med Inform 2006;75(2):173-81.

24. Ghinea G, Asgari S, Moradi A, Serif T. A Jinibased solution for electronic prescriptions. IEEE Trans Inf Technol Biomed 2006;10(4):794-802.

25. McDonald CJ, Tierney WM, Overhage JM, Martin DK, Wilson GA. The Regenstrief Medical Record System: 20 years of experience in hospitals, clinics, and neighborhood health centers. MD Comput 1992;9(4):206-17.

26. Despont-Gros C, Landau R, Rutschmann O, Simon J, Lovis C. The digital pen and paper. Evaluation and acceptance of a new data acquisition device in clinical settings. Methods Inf Med 2005;44(3):359-68.

27. Kuperman GJ, Bobb A, Payne TH, Avery AJ, Gandhi TK, Burns G, et al. Medication-related clinical decision support in computerized provider order entry systems: a review. J Am Med Inform Assoc 2007;14(1):29-40.

28. Schug SH, Redders M. [Health telematics projects in the perspective of the German federal states]. Bundesgesundheitsblatt Gesundheitsforschung Gesundheitsschutz 2005;48(6):649-56.

29. Schmidt K. [The electronic prescription and its consequences: physicians need waiting room like a railroad station]. MMW Fortschr Med 2006;148(38):58-9.

30. Sun-Microsystems. Jini Architectural Overview Technical white paper. 1999 [cited 14.04.2007]; Available from: http://www.sun.com/software/jini/ whitepapers/architecture.pdf

31. WHO. eHealth. 2005 [cited 14.04.2007]; Available from: http://www.who.int/healthacademy/media/en/
eHealth_EB_Res-en.pdf

32. Blobel B, Pharow P. A model driven approach for the German health telematics architectural framework and security infrastructure. Int J Med Inform 2007:76(2-3):169-75.

33. Koch S. Meeting the challenges - the role of medical informatics in an ageing society. Stud Health Technol Inform 2006;124:25-31.

34. Hersh WR, Hickam DH, Severance SM, Dana TL, Pyle Krages K, Helfand M. Diagnosis, access and outcomes: Update of a systematic review of telemedicine services. JTelemed Telecare 2006; 12 Suppl 2:S3-31.

35. Whitten P. Mickus M. Home telecare for COPD/ CHF patients: outcomes and perceptions. JTelemed Telecare 2007:13(2):69-73.

36. Maiolo C, Mohamed EI, Fiorani CM, De Lorenzo A. Home telemonitoring for patients with severe respiratory illness: the Italian experience. JTelemed Telecare 2003;9(2):67-71.

37. Lamothe L, Fortin JP, Labbe F, Gagnon MP, Messikh D. Impacts of telehomecare on patients, providers, and organizations. Telemed J E Health 2006; 12(3):363-9.

\section{Correspondence to:}

Dr.-Ing. Oliver J. Bott

Technical University of Braunschweig

Insitute for Medical Informatics

Muehlenpfordtstraße 23

D-38106 Braunschweig

Germany

Tel: +49531 3919505

Fax: +49531 3919502

E-mail: 0.bott@mi.tu-bs.de

\section{Appendix: Content Summa- ries of Selected Best Papers for the IMIA Yearbook 2007, Section Health Information Systems*}

\author{
Despont-Gros C, Landau R, Rutschmann 0, \\ Simon J, Lovis C \\ The digital pen and paper. Evaluation and \\ acceptance of a new data acquisition device \\ in clinical settings \\ Methods Inf Med 2005;44(3):359-68
}

Despont-Gros et al. in their study address the topic of suitable user interfaces for mobile data entry by evaluating a new data acquisition device in clinical settings: the digital pen and paper. This technology combines the use of a specific paper form with a digital pen that incorporates a small camera to map user entries to corresponding input fields of an electronic version of the form. For certain data input tasks this might be an alternative for classical portable devices like PDAs or laptops. The prospective interventional unblinded study conducted by DesontGros et al. evaluated acceptance and reliability of this technology. Acceptance was assessed using questionnaires and observations. Reliability was evaluated based on a comparison of the digital pen against scanner based analysis and double human blinded acquisition. The studies were conducted in the ER and in OB Anesthesia. Their results report a relative high user satisfaction concerning the new technology. Its reliability was high but lower than the reliability of scanner technology. The authors con-

* The complete papers can be accessed in the Yearbook's full electronic version, provided that permission has been granted by the copyright holder(s) 
clude that based on thoroughly designed acquisition forms digital pens are useful even in stressful clinical environments.

\section{Ghinea G, Asgari S, Moradi A, Serif T. A \\ Jini-based solution for electronic prescriptions}

\section{IEEE Trans Inf Technol Biomed \\ 2006;10(4):794-802}

Computer provider order entry (CPOE) systems with clinical decision support have the potential to improve patient safety and lower medication-related costs [27]. Many health information systems are equipped with such systems and several national eHealth infrastructure projects focus on introducing electronic prescriptions like e.g. Germany [28]. But even if electronic prescription seems to be a simple task, the development of a solution usable in daily routine is not. Publications concerning the health card based solution currently discussed in Germany assume that the time a health care professional needs to sign an electronic prescription will be 12 times higher than the time needed to sign a paper prescription, what would not be acceptable [29]. Thus sophisticated system concepts and user interfaces are needed that streamline the process of electronic prescriptions. The paper of Ghinea et al. proposes a Jinibased solution that utilizes concepts of ubiquitous computing to effectively support preparing, signing and communicating electronic prescriptions. Jini is a Java based framework for developing scalable and flexible distributed systems [30]. The proposed system bases on GP and pharmacy systems that are wirelessly connected with Jini-enabled mobile devices that a patient can use to store prescriptions and to communicate them to a pharmacy of his choice. Because the whole process including the contact to the pharmacy does not bases on handing over physical artifacts like a health card but solely uses wireless information exchange, the electronic prescription process is comparably efficient. The system has been positively evaluated with 15 Londonbased GPs and 28 patients based on questionnaires.

\section{Liu CT, Yang PT, Yeh YT, Wang BL}

The impacts of smart cards on hospital information systems-an investigation of the first phase of the national health insurance smart card project in Taiwan

\section{Int J Med Inform 2006;75(2):173-81}

The introduction of eHealth infrastructures to support cooperation of health care service providers more efficiently is currently part of many national health system strategies [1]. The WHO eHealth declaration of 2005 impressively demonstrated the need for such structures in all countries worldwide [31]. Thus there is an intensive discussion concerning organizational and technical aspects of health telematics platforms and many countries focus on health card based approaches like e.g. Germany [32]. Taiwan introduced electronic health insurance cards for patients in 2003 and the paper of Liu et al. reports the results of a questionnaire based study that investigates the impacts of introducing this technology on hospital information systems. Besides being used for identification and health services access the card carries some medical information like physician orders, prescriptions, and drug allergies. The introduction of the card required hospitals to integrate card readers and card access into their hospital information systems and to adapt their work flows correspondently. All hospitals in Taiwan were given the opportunity to fill in the questionnaire that assessed technical and organizational effects, the financial burden and the overall satis- faction with the new technology. The results report several technical and organizational problems like card and card reader problems, interface problems, prolonged service times, and an expenditure of up to 175 person days for adapting the hospital information system. Overall satisfaction with the project is moderate. The authors conclude that similar projects should invest early in public-awareness, and that technical maturity is of uppermost importance before introducing such technology in a broad range.

\section{Maglaveras N, Chouvarda I, Koutkias VG, Gogou G, Lekka I, Goulis D, Avramidis A, Karvounis C, Louridas G, Balas EA The Citizen Health System (CHS): a modular medical contact center providing quality telemedicine services}

\section{Int J Med Inform 2005 Mar;74(2-4):245-56}

IT-based telecare and home-care concepts are one approach to face health care system challenges like the aging society [33]. The last years a lot of telemedicine projects have focused on substituting face-to-face medical diagnostics and treatment and resulted in solutions that often (not always) have proven usability and have shown effects in terms of clinical outcome or cost efficiency [34]. This implies a need for systematically integrating telemedicine in health information system architectures [2]. The paper of Maglaveras et al. presents a concept of an eHealth infrastructure to support telemedicine and home care for a broad spectrum of chronically ill patients. It does not focus solely on supporting telemedicine for a certain disease related scenario and thus contributes to the discussion of general architectural aspects of such systems. The proposed Medical Contact Center (MCC) offers services for health care professionals (HCP) as well as for patients needing medical services. 
Main patient related services are health monitoring, education and communication with HCP. Services for HCP consist of patient administration, review of medical data and communication with patients. The middleware based architecture incorporates modules for alerting, rule based decision support, personalized education, communication using different channels, call centre access and sensor based signal processing and communication. The MCC technology has been evaluated in several trials in the context of diabetes and obesity, and cardiology. Basic facts concerning form and results of the evaluation are presented in the paper and underline the system's potential to increase the quality of healthcare services.

\section{de Toledo P, Jimenez S, del Pozo F, Roca J, Alonso A, Hernandez C \\ Telemedicine experience for chronic care in COPD}

\section{IEEE Trans Inf Technol Biomed}

\section{6; 10(3):567-73}

Home care for patients with chronic obstructive pulmonary disease (COPD) is subject to many telemedicine projects [35-37]. The paper of de Toledo et al. reports effects of using a telemedicine platform that bases on a shared electronic health record system (EHRS). The services offered for patients are telemonitoring of relevant biomedical parameters and symptoms, asynchronous and synchronous communication with a case manager using different communication channels, and access to educational material. Services for the professionals include web-based patient management, and ubiquitous EHRS access in the clinic or at the patient's home. The clinical outcome has been evaluated based on a one year lasting controlled, randomized clinical study with 157 patients. Besides recording readmissions, ER visits and mortality the health care professional's acceptance has been assessed using questionnaires. Additionally a costs analysis has been conducted. The study reveals a significant reduction in the number of readmissions in one year. The evaluation of system acceptance by health care professionals underlines ease of use of the system and its potential to improve patient care. The cost analysis gives rise to the assumption that the system's costs can be paid by the cost savings produced through the reduction of hospitalization days. Further information concerning usage patterns of the telemedicine system is provided. The authors conclude that telemedicine platforms like the one presented can play a major role in new strategies for home care based chronic disease management towards improving patient care without associated cost raises. 